\title{
Summer diarrhoea in African infants and children
}

\author{
R M ROBINS-BROWNE, C S STILL, M D MILIOTIS, N J RICHARDSON, H J KOORNHOF, \\ I FREIMAN, B D SCHOUB, G LECATSAS, AND E HARTMAN
}

Department of Microbiology, School of Pathology of the South African Institute for Medical Research and the University of the Witwatersrand, Johannesburg, Department of Paediatrics, Baragwanath Hospital, National Institute for Virology, Johannesburg, and Department of Microbiology, Institute for Pathology, University. of Pretoria, South Africa

Gastroenteritis continues to pose a serious problem throughout the developing world, where, in many communities, diarrhoea constitutes the main cause of infant mortality. Repeated attacks of diarrhoea also aggravate the already poor nutritional status of underprivileged children, with a consequent heightened susceptibility to infectious diseases. ${ }^{1}$

In South Africa during 1965, the last year for which published figures are available, 78.8 black infants per 1000 live births died during the first year of life compared with 22.4 whites. $^{2}$ Approximately one-third of the excess mortality in black infants was directly attributable to gastroenteritis. ${ }^{2} \mathrm{Al}-$ though recent unpublished data suggest an improvement in the situation, the incidence of childhood diarrhoea in South Africa remains high.

At Baragwanath Hospital, on the outskirts of Johannesburg, a 35-bed paediatric rehydration centre has been established for infants with gastroenteritis (Fig. 1). Most admissions to this unit take place in summer at the height of the rainy season (Fig. 2), a finding which contrasts with the predominance of winter diarrhoea in North Americans, Europeans, and southern African whites. ${ }^{3-5}$

In this paper we report results of a comprehensive study into the aetiology of acute summer diarrhoea in infants and children admitted to Baragwanath Hospital. Our investigations included a search for enterotoxigenic bacteria and rotaviruses, as well as for traditional enteropathogens. Prompted by the recent upsurge of interest in the role of Campylobacter fetus in infantile enteritis, ${ }^{6}$ we also undertook a pilot study of the prevalence of this bacterium in children with diarrhoea.

\section{Subjects}

Patients. These were black infants and children under 2 years of age admitted to Baragwanath Hospital for treatment of dehydration during December 1976 and January 1977. Parents were questioned regarding the current illness, medical history, and feeding practices. Patients with diarrhoea lasting more than 10 days and those known to have received antibiotics for the current illness were excluded from the study. Each child received a general physical examination and was weighed. Nutritional status was assessed clinically and by reference to growth charts. Dehydration was graded as mild (sunken eyes or minimal skin turgor changes), moderate (sunken eyes and fontanelle, and poor skin turgor), or severe (features of moderate dehydration associated with clinical shock or acidosis).

Control subjects. Controls were matched for age and selected from children attending the paediatric outpatient department at Baragwanath Hospital during the study period. Most of these children were suffering from minor respiratory tract infections or exanthemata, and none gave a history of diarrhoea during the preceding 4 weeks. 


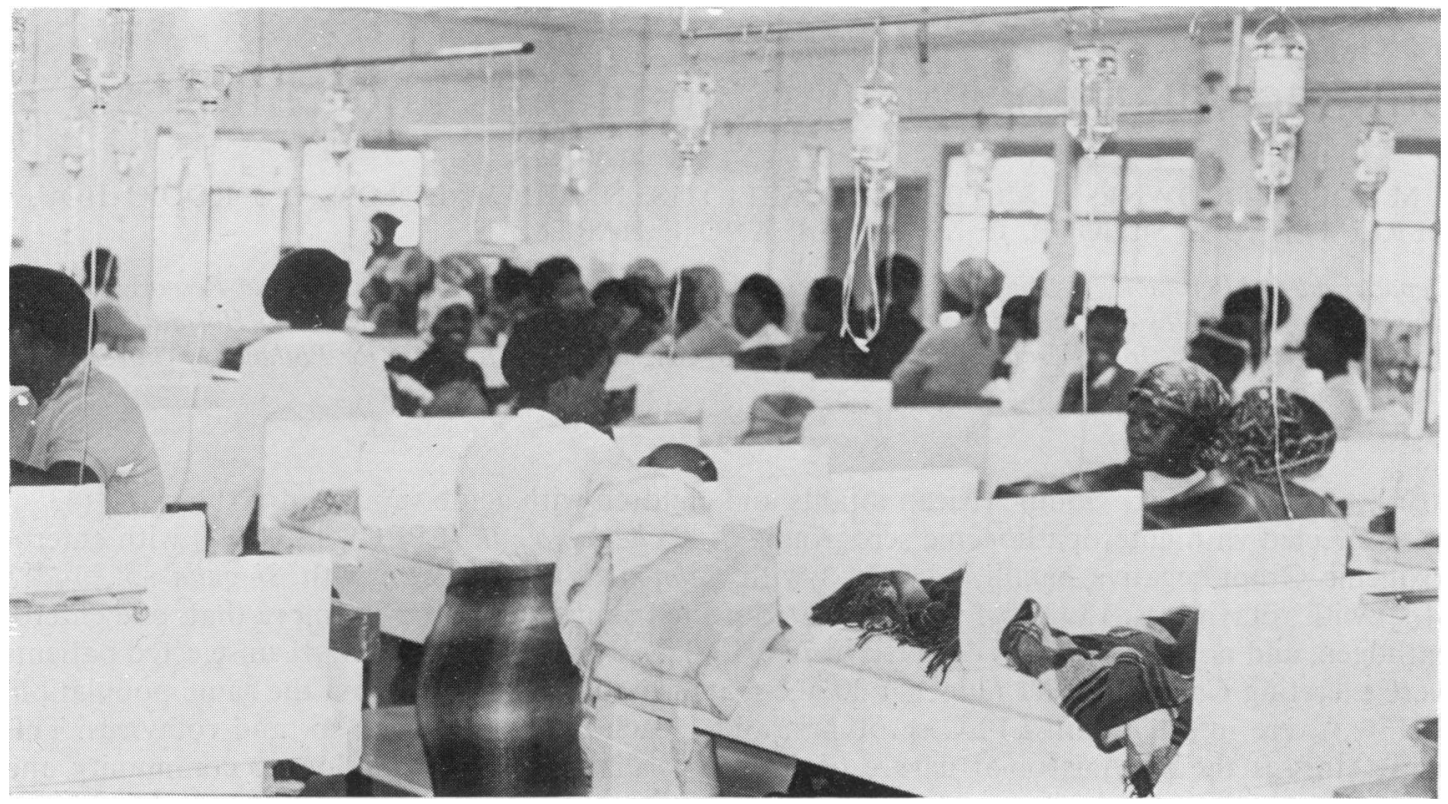

Fig. 1 The rehydration centre at Baragwanath Hospital.

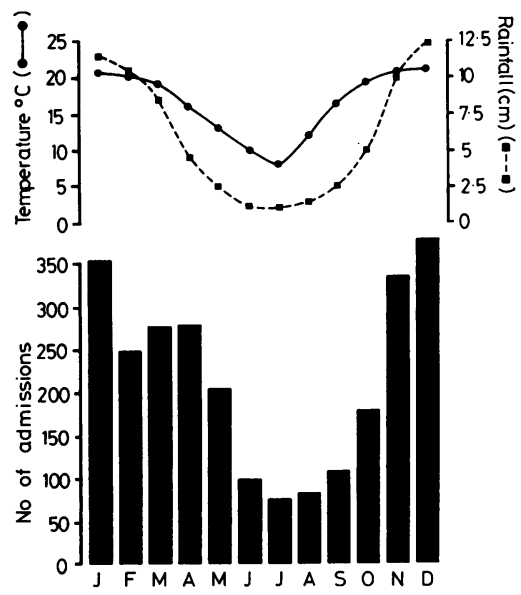

Fig. 2 Mean number of children admitted to the rehydration centre at Baragwanath Hospital each month from 1975 to 1977 inclusive; and the mean monthly temperature and rainfall in Johannesburg.

About two-thirds of the infants and children were under 1 year of age, and $60 \%$ were boys.

\section{Methods}

Specimen collection. Fresh stool specimens were collected from patients and control subjects after induction with a sterile cotton swab or gloved finger. If this failed (as it did in 2 of 70 patients and in 23 of 30 controls), rectal swabs were obtained.

Laboratory procedures. Microscopical examination of faeces for inflammatory cells was performed by the method of Harris et al. ${ }^{7}$ Standard bacteriological procedures were used to isolate salmonellae, shigellae, and Escherichia coli. Cold enrichment was used for the isolation of Yersinia enterocolitica. Examination for $C$. fetus was performed on 41 consecutive patients' stools by the method reported elsewhere. $^{8}$

Between 5 and 10 colonies of different morphological types, comprising at least 5 lactose-fermenters and up to 5 nonlactose-fermenters, were studied further. Each colonial type, $\mathbf{5 8 3}$ from patients and 281 from controls, was characterised biochemically and tested for enterotoxigenicity and invasiveness. E. coli, salmonella, and shigella isolates were serogrouped by slide agglutination with commercial antisera (Wellcome; Hoechst). E. coli which exhibited strong and rapid agglutination with O25:K11, O26:K60, O44:K74, O55:K59, O86:K61, O111:K58, O112:B11, O114:K-, O119:K69, O124:K72， O125:K70， O126:K71， O127:K63, O128:K67, or O142:K86 grouping sera were designated 'classical' enteropathogenic $E$. coli (EPEC).

Enterotoxin assays were performed on bacteria stored frozen or freeze-dried after a minimum 
number of subcultures. Bacteria were cultivated in casamino acid-yeast extract broth overnight at $37^{\circ} \mathrm{C}$ with shaking at $180 \mathrm{rev} / \mathrm{min} .^{9}$ Filtrates sterilised by Millipore filtration $(0.22 \mu \mathrm{m})$ were tested for ST in suckling mice, ${ }^{10}$ and for LT in $\mathrm{Y}-1$ adrenal and Chinese hamster ovary tissue cultures. ${ }^{11-12}$ All assays were performed in triplicate in parallel with control samples of known enterotoxigenicity. Positive results were confirmed by repeating each test with and without heating the sample to $60^{\circ} \mathrm{C}$ for 30 minutes.

Bacterial invasiveness for epithelial cells was examined in the guinea-pig keratoconjunctivitis test. ${ }^{13}$

Electron microscopical examination of stool samples for viruses was performed as described previously. ${ }^{14}$

\section{Results}

A possible cause for diarrhoea was identified in $48(69 \%)$ of the 70 patients investigated. $35(50 \%)$ yielded a single pathogen, comprising 18 nonenterotoxigenic EPEC, 8 enterotoxigenic Gramnegative bacilli (ETGNB) (including 3 EPEC serogroups), 5 salmonellae, 3 shigellae, and 1 rotavirus. $13(19 \%)$ patients showed more than one enteropathogen. In 9 such cases at least one pathogen was an EPEC. Other mixed infections were 2 patients with salmonellae and ETGNB, 1 with salmonella and rotavirus, 1 with Shigella dysenteriae and an ETGNB, and 1 with Shigella flexneri and haematophagous trophozoites of Entamoeba histolytica.

Altogether EPEC were detected in 30 patients, ETGNB in 13, salmonellae in 12, shigellae in 6 , rotaviruses in 3, and Ent. histolytica in 1 (Table 1). This analysis excludes $C$. fetus which was recovered from $6(15 \%)$ of 41 randomly chosen patients. Two C. fetus isolates were obtained from patients who were also excreting salmonellae and EPEC. One isolate each was obtained from patients simultaneously infected with an EPEC strain and rotavirus respectively; and 2 were recovered from patients in whom no other pathogen was detected.

Table 1 Distribution of enteropathogens in patients with diarrhoea compared with control subjects

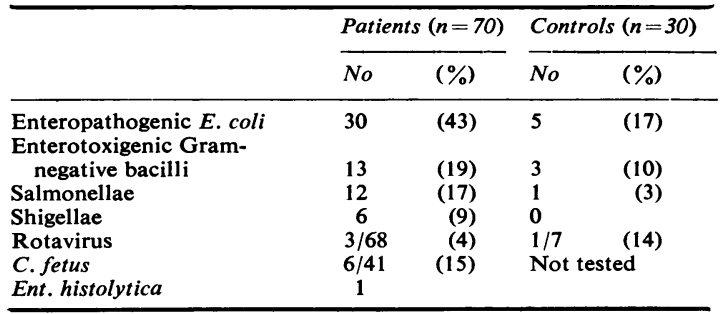

No pathogens were detected in specimens from $21(70 \%)$ control subjects. Of the remainder, $8(27 \%)$ were excreting one pathogen (5 EPEC, 2 ETGNB, and 1 salmonella) and $1(3 \%)$ was harbouring two pathogens (rotavirus and ETGNB) (Table 1). Significantly more patients with diarrhoea were excreting EPEC serotypes than control subjects $\left(\chi^{2}\right.$ Yates's correction $\left.=5 \cdot 23, P<0.03\right)$. No $Y$. enterocolitica or enteroinvasive strains of $E$. coli were obtained from either the patient or control groups in this study.

Of the 583 Gram-negative bacilli recovered from patients, $E$. coli accounted for $299(51 \%)$, of which $28(9 \%)$ were enterotoxigenic, $85(28 \%)$ agglutinated with EPEC antisera, and $73(24 \%)$ autoagglutinated in saline and were accordingly nontypable. Control subjects gave $121 \mathrm{E}$. coli isolates, of which $7(6 \%)$ produced enterotoxin, $8(7 \%)$ were EPEC serotypes, and $38(31 \%)$ were nontypable. Although the proportion of $E$. coli among all Gram-negative bacilli identified from patients $(51 \%)$ was significantly greater than that from controls $(43 \%)\left(\chi^{2}=5 \cdot 14\right.$, $\mathrm{P}<0 \cdot 05)$, EPEC accounted for a very much larger proportion of patients' $E$. coli (85 of 299) than in controls $\left(8\right.$ of 121) $\left(\chi^{2}=23 \cdot 78, P<0 \cdot 001\right)$.

The EPEC strains recovered during this investigation were of 13 different $\mathrm{O}$-serogroups, and the most common were 0126 (6 patients) and 0128 (5 patients). Other EPEC serogroups recovered from patients were O55 (3), O114 (3), O86 (2), O112 (2), 0125 (2), 0142 (2), and one each of $\mathrm{O} 25, \mathrm{O} 26$, O111, O119, and O127. The 5 EPEC from control subjects comprised two isolates of 0142 , and one each of 086,0111 , and 0125 .

The salmonella and shigella isolates obtained in this study were also diverse. The 13 salmonellae were made up of S. typhimurium (5), S. kentucky (3), $S$. muenchen (2), S. newport (1), S. sarajane (1), and $S$. irumu (1). Six shigella isolates comprised $S h$. flexneri (3), Sh. sonnei (2), and Sh. dysenteriae (1).

Of the 16 enterotoxigenic Gram-negative bacilli recovered in this study, 13 were $E$. coli, 3 of which were EPEC of serogroups O128 (2) and O112 (1). Three $E$. coli isolates produced LT only, 3 ST only, and 7 produced both LT and ST. Two patients and 1 control subject yielded enterotoxigenic strains of Enterobacter sp., two of which were ST-producing only, and one produced only LT. The mouse adrenal and Chinese hamster ovary tissue culture assays were comparably efficient in detecting LTproducing bacteria, and it is probably unnecessary to use both systems routinely.

When clinical data of patients were grouped according to infecting agent some trends were apparent. EPEC were detected more frequently in younger patients and more often in boys. Only 1 
patient was exclusively breast fed, while $49(70 \%)$ patients received no breast milk at all. In contrast, almost half $(47 \%)$ of control subjects were entirely or partially breast fed.

The presence of leucocytes in the stool was common in shigella infections but rare in infections with enterotoxigenic bacteria. In infections due to other agents their presence was erratic. Neither fever, vomiting, nor the severity of dehydration was related to the nature of the infecting agent.

\section{Discussion}

The results of this study show the complex nature of gastroenteritis in indigenous black South African children. EPEC serogroups emerged as the single most important cause of diarrhoea in this population, a finding which confirms the results of earlier studies at Baragwanath hospital (Table 2).

Recently doubt has been cast on the enteropathogenicity of EPEC, particularly after reports that these bacteria generally do not produce classic enterotoxins and are not invasive in experimental animals. ${ }^{15-16}$ The finding that these bacteria are associated with a distinctive clinical illness however, ${ }^{17}$ and the demonstration of the ability of some strains to cause diarrhoea in volunteers, ${ }^{18}$ has reaffirmed their enteropathogenic role. The mechanism whereby EPEC cause diarrhoea is not clear, although there is evidence for their ability to produce toxins which are nonreactive in the standard suckling mouse and tissue culture assays. ${ }^{19}$ The finding of faecal leucocytes in 13 of 24 children infected with EPEC however, suggests that enterotoxigenicity is not the only pathogenic mechanism of diarrhoea caused by these bacteria.

Other traditional enteropathogens, salmonella and shigella, although numerically less important than EPEC, continue to be responsible for cases of childhood diarrhoea in Johannesburg. The incidence of shigellosis however, has fallen appreciably since $1959-60$, particularly in children under age 1 year. $^{20}$

Table 2 Recovery of enteropathogenic E. coli from children with diarrhoea and from age-matched controls

\begin{tabular}{|c|c|c|c|c|c|c|}
\hline \multirow[t]{2}{*}{ Year } & \multicolumn{2}{|c|}{ Patients } & \multicolumn{2}{|c|}{ Controls } & \multirow[t]{2}{*}{$P$} & \multirow[t]{2}{*}{ Reference } \\
\hline & No & $(\%)$ & $N o$ & $(\%)$ & & \\
\hline $\begin{array}{l}1959 / 60 \text { (summer) } \\
1974 / 5 \text { (all year) }\end{array}$ & $\begin{array}{l}52 / 120 \\
55 / 191\end{array}$ & $\begin{array}{l}(43) \\
1(29)\end{array}$ & $\begin{array}{l}14 / 60 \\
30 / 178\end{array}$ & $\begin{array}{l}(23) \\
(17)\end{array}$ & $\begin{array}{l}<0.02^{*} \\
<0.01^{*}\end{array}$ & $\begin{array}{l}\text { Roux et al. }{ }^{20} \\
\text { Freiman } \\
\quad \text { et al. } .^{28}\end{array}$ \\
\hline Summer & $45 / 134$ & $4(34)$ & $27 / 147$ & 7 (18) & $<0.01^{*}$ & $\begin{array}{l}\text { Freiman } \\
\text { et } \text { al. } 28\end{array}$ \\
\hline Winter & $10 / 57$ & (18) & $3 / 31$ & (10) & $>0.5 \dagger$ & $\begin{array}{l}\text { Freiman } \\
\text { et al.28 }\end{array}$ \\
\hline 1976/7 (summer) & $30 / 70$ & (43) & $5 / 30$ & (17) & $<0.03^{*}$ & Present study \\
\hline
\end{tabular}

*Determined by $\chi^{2}$-test with Yates's correction.

†Determined by Fisher's exact test.
The contribution of enterotoxigenic $E$. coli and other enterotoxigenic Gram-negative bacilli to summer diarrhoea in Johannesburg children requires further clarification. Although $13(19 \%)$ patients in the present study were excreting enterotoxigenic bacteria, and in 8 patients these were the sole pathogen, enterotoxigenic bacteria were also recovered from $3(10 \%)$ subjects in the control group. Moreover, the proportion of enterotoxigenic strains among $E$. coli from patients (28 of 583) was not significantly different from that from controls ( 7 of 121) $(\mathrm{P}>0 \cdot 5)$.

In temperate countries rotaviruses account for most episodes of paediatric diarrhoea, especially during the winter. ${ }^{3}$ Their reported frequency in warm countries varies between 0 and $49 \% .{ }^{21-23}$ By using electron microscopical examination, a comparatively insensitive technique, we found rotaviruses in only 3 of 68 patients with acute summer diarrhoea. This may be misleading, as delays between the onset of diarrhoeal symptoms and the admission of children to hospital were common, with consequent reduction in virus shedding. ${ }^{23}$ Methods of virus detection more sensitive than electron microscopical examination-such as radioimmunoassay, ${ }^{24}$ enzyme-linked immunosorbent assay, ${ }^{25}$ or reverse complement fixation-are likely to give higher yields. ${ }^{23}$

No pathogen was detected in $22(31 \%)$ patients in this study. Diarrhoea due to noninfective causes or extraintestinal infection may have accounted for some of these cases. In addition, infection with Giardia lamblia, Ent. histolytica, or viruses other than rotaviruses, may have contributed some cases of diarrhoea, as our investigation did not include a systematic search for these agents. The one patient in whom amoebiasis was diagnosed was discovered fortuitously.

C. fetus was found in 2 of 11 patients in whom no other pathogen was detected. A recently completed survey at Baragwanath Hospital showed that $C$. fetus subsp. jejuni is significantly associated with infantile gastroenteritis, especially in children younger than 8 months. ${ }^{8}$

Concurrent infection with more than one pathogen was present in almost one-fifth of patients in this study. These cases, which probably represent simultaneous infections from a multicontaminated source, further complicate the already complex problem of childhood gastroenteritis.

This investigation shows that summer diarrhoea in South Africa is caused by many pathogenic micro-organisms. The wide variety of enteropathogens recovered from patients attests to the role played by environmental factors in the transmission of bacterial agents causing diarrhoea. In developing 
communities gastroenteritis is multifactorial with major contributions made by poor hygiene, undernutrition, and overcrowding. The frequency with which enteropathogens were recovered from control subjects substantiates this view.

Lack of knowledge of the infectious nature, prevention, and correct treatment of diarrhoea adds to the incidence and severity of gastroenteritis in Johannesburg blacks. Several mothers of patients in this study confessed to having consulted traditional tribal medical practitioners (witchdoctors) before attending Baragwanath Hospital. This resulted in some children receiving ill-advised folk remediessuch as soap, milk, garlic, or crushed stone enemasand other undisclosed medicaments.

No immediate solution to the problem of childhood diarrhoea in developing communities is apparent. Although a vaccine to prevent diarrhoea due to some strains of $E$. coli seems feasible, ${ }^{26}$ the polymicrobial nature of diarrhoea does not augur well for its success. In affluent countries, a striking decline in death from gastroenteritis has taken place in the absence of specific preventive or curative measures, ${ }^{27}$ suggesting that improved nutrition, education, and living conditions will benefit affected populations more than efforts at specific prevention.

We thank Dr $\mathrm{H}$ Kassel for assistance with the collection of specimens, and Dr R Bradley Sack, Johns Hopkins University, Baltimore, USA, for providing Y-1 adrenal culture cells.

This study was supported in part by a grant from the South African Medical Research Council.

\section{References}

1 Mata L J. Malnutrition-infection interactions in the tropics. Am J Trop Med Hyg 1975; 24: 564-74.

2 Spencer I W F, Coster M E E. The epidemiology of gastroenteritis in infancy. Part I. S Afr Med J 1969; 43: 1391-7.

3 Kapikian A Z, Kim H W, Wyatt R G, et al. Human reovirus-like agent as the major pathogen associated with 'winter' gastroenteritis in hospitalized infants and young children. N Engl J Med 1976; 294: 965-72 .

4 Cruickshank R. Enteric infections: gastroenteritis, dysentery, typhoid, cholera. In : Cruickshank R, Standard $\mathrm{K}$ L, Russell H B L, eds. Epidemiology and community health in warm climate countries. Edinburgh: Churchill Livingstone, 1976: 107-15.

5 Cruickshank J G, Zilberg B. Winter diarrhoea and rotaviruses in Rhodesia. S Afr Med J 1976; 50: 1895-6.

6 Skirrow M B. Campylobacter enteritis: a 'new' disease. Br Med J 1977; ii: 9-11.

7 Harris J C, DuPont H L, Hornick R B. Fecal leukocytes in diarrheal illness. Ann Intern Med 1972; 76: 697-703.

8 Bokkenheuser V D, Richardson N J, Bryner J H, et al. Detection of enteric campylobacteriosis in children. J Clin Microbiol 1979; 9: 227-32.

9 Evans D G, Evans D J, Jr, Pierce N F. Differences in the response of rabbit small intestine to heat-labile and heatstable enterotoxins of Escherichia coli. Infect Immun 1973; 7:873-80.

10 Dean A G, Ching Y-C, Williams R G, Harden L B. Test for Escherichia coli enterotoxin using infant mice: application in a study of diarrhea in children in Honolulu. J Infect Dis 1972; 125: 407-11.

11 Sack D A, Sack R B. Test for enterotoxigenic Escherichia coli using $\mathrm{Y} 1$ adrenal cells in miniculture. Infect Immun $1975 ; 11$ : 334-6.

12 Guerrant R L, Brunton L L, Schnaitman T C, Rebhun L I, Gilman A G. Cyclic adenosine monophosphate and alteration of Chinese hamster ovary cell morphology: a rapid, sensitive in vitro assay for the enterotoxins of Vibrio cholerae and Escherichia coli. Infect Immun 1974; 10: $320-7$.

13 Sereny B. Experimental Shigella keratojunctivitis: a preliminary report. Acta Microbiol Acad Sci Hung 1955; 2: 293-6.

14 Schoub B D, Koornhof H J, Lecatsas G, et al. Letter: Viruses in acute summer gastroenteritis in black infants. Lancet 1975; i: 1093-4.

15 Goldschmidt M C, DuPont H L. Enteropathogenic Escherichia coli: lack of correlation of serotype with pathogenicity. J Infect Dis 1976; 133: 153-6.

16 Echeverria P D, Chang C P, Smith D. Enterotoxigenicity and invasive capacity of 'enteropathogenic' serotypes of Escherichia coli. J Pediatr 1976; 89: 8-10.

17 Gurwith M J, Wiseman D A, Chow P. Clinical and laboratory assessment of the pathogenicity of serotyped enteropathogenic Escherichia coli. J Infect Dis 1977; 135: 736-43.

18 Levine M M, Bergquist E J, Nalin D R, et al. Escherichia coli strains that cause diarrhoea but do not produce heatlabile or heat-stable enterotoxins and are non-invasive. Lancet 1978; i: 1119-22.

19 Klipstein F A, Rowe B, Engert R F, Short H B, Gross $R \mathbf{J}$. Enterotoxigenicity of enteropathogenic serotypes of Escherichia coli isolated from infants with epidemic diarrhea. Infect Immun 1978; 21 : 171-8.

20 Roux P, Kahn E, Malherbe H, Cassel R. The role of enteropathogenic bacteria and viruses in acute diarrhoeal disorders of infancy and childhood in Johannesburg. I. Summer diarrhoea. S Afr Med J 1965; 37: 256-9.

21 Rowland M G M, Davies H, Patterson S, et al. Viruses and diarrhoea in West Africa and London: a collaborative study. Trans R Soc Trop Med Hyg 1978; 72: 95-8.

22 Viera de Torres B, Mazzali de Ilja R, Esparza J. Epidemiological aspects of rotavirus infection in hospitalized Venezuelan children with gastroenteritis. Am J Trop Med Hyg 1978; 27 : 567-72.

23 Schoub B D, Greeff A S, Lecatsas G, et al. A microbiological investigation of acute summer gastroenteritis in black South African infants. J Hyg (Camb) 1977; 78: 377-85.

24 Kalica A R, Purcell R H, Sereno M M, et al. A microtiter solid phase radioimmunoassay for detection of the human reovirus-like agent in stools. J Immunol 1977; 118: 1276-9.

${ }_{25}$ Yolken R H, Kim H W, Clem T, et al. Enzyme-linked immunosorbent assay (ELISA) for detection of human reovirus-like agent of infantile gastroenteritis. Lancet 1977; ii: $263-7$.

26 Nagy B, Moon H W, Isaacson R E, To C-C, Brinton C C. Immunization of suckling pigs against enteric enterotoxigenic Escherichia coli infection by vaccinating dams with purified pili. Infect Immun 1978; 21 : 269-74.

27 McDermott W. Modern medicine and the demographicdisease pattern of overly traditional societies: a technologic misfit. J Med Educ 1966; 41: Supplement, 137-62. 
28 Freiman I, Hartman E, Kassel H, et al. A microbiological study of gastroenteritis in black infants. $S A f r$ Med J 1977; 52: 261-5.

Correspondence to Dr R Robins-Browne, Department of Microbiology, University of Natal, PO Box 17039, Congella 4013, South Africa.

Received 11 September 1979

\section{Commentary}

\section{J A WALKER-SMITH}

\section{Queen Elizabeth Hospital for Children, London}

Since the exciting observation in Melbourne by Bishop et al. ${ }^{1}$ that rotavirus is a significant aetiological agent for childhood gastroenteritis, this virus has been reported in the stools of many such children in developed countries, particularly during the winter. ${ }^{2-4}$ However, reports from the developing world have varied greatly both for the prevalence of rotavirus and for the prevalence of conventional enteropathogenic serogroups of E. coli (EPEC). For example, Taylor et al. ${ }^{8}$ found rotavirus in $45 \%$ of children with diarrhoea in a rural treatment centre in Bangladesh, whereas Robins-Browne et al. in Johannesburg, in the above report, found EPEC in $43 \%$ of black infants with acute summer diarrhoea. It seems unlikely that this difference in prevalence of aetiological agents is due to the method of detection, and most probably it does represent a genuine fact. Past experience in developed countries may be helpful! It is obvious that in Britain there has been a major change in the aetiology of gastroenteritis, and in the pattern of prevalence. Summer diarrhoea in the east end of London was recorded at the Queen Elizabeth Hospital for Children from 1885 to 1937 and there was a mortality of $40-50 \%$ for inpatients aged under 2 years, but the pattern of summer outbreaks ceased in 1937 and did not recur. ${ }^{5}$ The 1953 MRC multicentre trial of prophylactic antibiotics in infantile gastroenteritis reported a $37 \%$ incidence for the serotypes of E. coli, O111 and O55, the only two known at that time. By 1967 the incidence of these two serotypes had declined to $4 \%$ of infantile gastroenteritis in Manchester, ${ }^{6}$ and during the year August 1976-7 at Queen Elizabeth Hospital for Children, only $4 \%$ of 544 children with gastroenteritis had one of the larger number of currently recognised strains of EPEC identified in their stools. Indeed now in east London, instead of a summer peak for gastroenteritis there is a winter peak ${ }^{7}$ and the rotavirus has been recognised as a significant and important aetiological agent during this winter peak, with $50 \%$ of stools examined during the winter months containing this virus. In Sydney, the winter peak in gastroenteritis admissions was first observed in 1964, having not been present in the immediately preceding years (D Dorman, 1972, personal communication). Thus major changes over the years have taken place in Australia and Britain, both in the pattern of prevalence and in the aetiology of infantile gastroenteritis. Social and environmental factors have obviously played a major role in producing these changes.

While there is little doubt that improved nutrition, education, and living conditions do lead to great improvement in mortality and prevalence of childhood gastroenteritis, yet in east London such improvements have not led to a disappearance of gastroenteritis, although the prevalence of $E$. coli enteritis has fallen so strikingly and 'summer diarrhoea' has gone. Indeed the emergence of a winter peak in admissions in east London and in other Western communities has been unexpected. There is a clear need to study the present epidemiology of gastroenteritis in childhood throughout the world and within the UK itself to take account of the geographical variations in prevalence, and the implication such variations may have both for aetiology and prevention. Thus it would seem probable that social and environmental factors are important in the difference between Bangladesh and Johannesburg. An investigation of these factors is urgently needed.

\section{References}

1 Bishop R F, Davidson G P, Holmes I H, Ruck B J. Virus particles in epithelial cells of duodenal mucosa from children with acute non-bacterial gastroenteritis. Lancet 1973; ii: $1281-3$.

2 Davidson G P, Bishop R F, Townley R R W, Holmes I H, Ruck B J. Importance of a new virus in acute sporadic enteritis in children. Lancet 1975 ; i: 242-6.

3 Hamilton J R, Gall D G, Butler D G, Middleton P J. Viral gastroenteritis: recent progress, remaining problems. In: Acute diarrhoea in childhood. Ciba Foundation Symposium 42 (new series). Amsterdam: Elsevier, 1976: 209-22.

4 Flewett T H, Bryden A S, Davies H. Virus particles in gastroenteritis. Lancet 1973; ii: 1497.

5 Back E H, Levin S. Paediatrics of the past. $\mathrm{Br} \mathrm{Med} \mathrm{J}$ 1954; ii: 406-8.

6 Ironside A G. Gastroenteritis in infancy. Br Med J 1973; i: 284-6.

7 Walker-Smith J A. Rotavirus gastroenteritis. Arch Dis Child 1978; 53: 355-62.

8 Taylor P R, Merson M H, Black R E, et al. Oral rehydration therapy for treatment of rotavirus diarrhoea in a rural treatment centre in Bangladesh. Arch Dis Child 1980 ; 55: 376-9. 